\title{
Teacher with Different Meta-Emotion Level: Their Understanding of and Responses to Children's Negative Emotions
}

\author{
LingLing Liu \\ School of Education Science, Hunan Normal University, Changsha, 41000, China \\ *Corresponding author.Email:melody600@outlook.com
}

\begin{abstract}
In this study, 223 teachers were measured using the Meta-emotion Scale, and were then classified into two groups: high meta-emotional levels and low meta-emotional levels. Direct observation and interviews were used to explore their effect on children's negative emotions, such as sadness and anger. The results suggest that both two groups of teachers have developed a proper understanding of students' negative emotions while teachers with higher meta-emotional levels provided more detailed emotional expressions. In terms of emotional education, both groups showed an overall scientific attitude and the higher meta-emotional group presented more purposeful and systematic behaviors. Concerning educational practices, the teachers with higher meta-emotional levels can respond to children's negative emotions in a more supportive way.
\end{abstract}

Keywords: meta-emotions, negative emotions, emotional awareness, emotional response, emotional education

\section{INTRODUCTION}

Meta-emotion was first proposed by Gottman (1996) ${ }^{[1]}$ in a study on how parents can deal with their children's emotions. This kind of meta-emotions refers to a specific set of emotional responses, awareness, understanding, evaluation, and application of the individual's own or others' various emotional behaviors, with the function of perceiving and directing the expressions of emotions ${ }^{[2]}$. A Chinese scholar $\mathrm{Xu}$ Yuanli also draws on the relevant theory and proposed that meta-emotion is the subject's ability to monitor the emotions of himself, as well as to analyze and regulate the causes, processes, and consequences of emotion's emergence ${ }^{[3]}$. At present, scholars at home and abroad have not deeply examined the field of the meta-emotion, most of which is reflected by the common measuring scales, such as Salovey's Meta-emotional Scale (TMMS ) evaluating three dimensions of emotional attention, emotional clarity, and emotional recovery. Among those Chinese scholars who based their studies on the Salovey scale, Qi et al. demonstrate congruous homogeneity validity, structural validity, and standard validity in the revision of the scale ${ }^{[4]}$.
Judging from the existing literature, there are not sufficient empirical studies on meta-emotion, and most of them are merely associated with parental behaviors in the field of education. For example, the level of parents' meta-emotion can affect 1) children's learning process of identifying and positioning their feelings, 2) children's physiological and behavioral competencies of regulating their emotions, and 3) children's adjustment strategies to respond to others' emotions (Debaryshe \& Fryxell, 1998). Although the literature on the role of parental meta-emotions in children's affective socialization is readily available and abundant, little is currently known about how teachers' meta-emotions influence children's emotional development and about how teachers take actions to provide emotional support in the classroom. Early childhood is a critical period for developing children's emotional abilities. As children's closest companions other than their parents, teachers can affect the development of students' emotional competencies by their own emotional levels and the way they respond to young children's emotions. Fortunately, an increasing number of scholars have begun to pay attention to the important role of teachers in promoting children's emotional development (Kienbaum, 2001; 
Rabineau, 2004 ). For example, Rabineau (2004) suggested that teachers' acceptance and support for children are the essential factors for protecting those children from high-pressure family environments, thereby promoting them to better regulate their emotions. In addition, the higher the teacher's support for children's emotional regulation, the less aggressive behavior and problems in interpersonal adjustment the children will have (Schoiack, 2000 ). Lin Wenting ( 2008 ), after studying the emotional relationship between children and teachers, pointed out that teachers' emotional cognition influence children's affective development, and suggested that kindergartens should strengthen teachers' emotional education and improve their emotional management capabilities.

The teachers' own perception of emotion can also serve as a significant element, especially how they respond to children's negative emotions. Relevant practical research shows that teachers' ability to manage their emotions and the levels of their emotional awareness is highly correlated with the way they handle children's passive attitudes ${ }^{[7]}$. However, many studies have shown that teachers' responses to children's negative feelings are neither appropriate nor rational ${ }^{[8][9][10]}$. As Zhe ( 2018 ) has suggested, when teachers are confronted with children's negativity, their strategies are mainly regulatory but lacking flexibility [11]. Most of these studies are directed at teachers' concepts or behavior individually instead of integrating the relationship between them in an organic entirety. Therefore, this study aims to screen out teachers with different meta-emotional levels through questionnaires and then interview them and observe their differences in how they respond to children's negative emotions, including their cognition of children's negativity, the way they deal with children's negativity, and the content they teach about negative emotions in the class. At the same time, the typical negative emotions, anger, and sadness, are chosen because these two emotions are common types of human emotions, which also reflect children's ability to adapt to the environment ${ }^{[12]}$. Coping with anger and sadness is normal work in teachers' daily teaching engagement, and it is not easy for them to notice that they are being observed, which is conducive to obtaining real data and conducting more extensive research.

\section{STUDY DESIGN}

\subsection{Research object}

In this study, a total of 223 teachers from 4 kindergartens were surveyed using the Meta-Emotional Scale (TMMS) revised by Qi Yan et al. (2003). The scale consists of 3 subscales, namely, emotional attention, emotional discrimination, and emotional recovery. For example, "I think about my emotions a lot" belongs to emotional attention; "I usually know how I feel about things" belongs to emotion discrimination; "No matter how bad I feel, I try to look on the bright side" belongs to emotional recovery. Each item is scored on a five-point Likert Scale from very disagree to very agree. The coefficients of the total scale and the subscale have reached 0.6 or more, demonstrating objective reliability and validity. A total of 223 questionnaires were distributed with 214 validly returned and four teachers in the high meta-emotional group and the low meta-emotional group were separately screened. The selection criteria were based on teachers who scored in the top twenty-five percent and bottom twenty-five percent of the score range and who volunteered to participate in the study.

Table 1: Basic situation of teachers

\begin{tabular}{llllll}
\hline & Gender & Age & $\begin{array}{l}\text { Teaching } \\
\text { age }\end{array}$ & $\begin{array}{l}\text { Teaching } \\
\text { class }\end{array}$ & $\begin{array}{l}\text { Garden } \\
\text { type }\end{array}$ \\
\hline T1 & Female & 30 & 9 & $5-6$ & Private \\
\hline T2 & Female & 29 & 7 & $4-5$ & Public \\
\hline T3 & Female & 46 & 24 & $3-4$ & Public \\
\hline T4 & Female & 38 & 16 & $5-6$ & Public \\
\hline
\end{tabular}

\subsection{Research methods}

\subsubsection{Observation method}

After screening out the high meta-emotional group and the low meta-emotional group, the researcher and another graduate student observed the four teachers as non-participatory observers for 120 minutes each over four days. Recorded through the technique of event sampling, the observation focused on the target teacher's verbal and non-verbal responses to children's expressions of sadness and anger. The observation area is about 1 meter away from the target teacher. The recording was activated when the teacher responded to the students' emotions and stopped when the children left the area where the emotional event occurred or when they changed the state of emotion.

\subsubsection{Interview method}

After conducting on-site observations, the researchers used lunchtime to interview four teachers for 40-60 minutes and recorded the interviews using a mobile phone. The purpose of the interviews was to explore 1) how kindergarten teachers think about children's negative emotions; 2) how they deal with these negative feelings; 3 ) whether and what they try to teach young children about negative emotions in their daily lessons. 


\subsubsection{Data processing}

Based on the 93 incidents of children's sadness and anger collected, the researchers analyzed and process the authentic data: teachers' diverse responding methods according to their classified groups by using SPSS 18.0.

\section{RESEARCH RESULTS AND ANALYSIS}

\subsection{Teachers' attitudes towards children's sadness and anger}

\subsubsection{Views on young children's sadness}

Both groups of teachers believed that sadness is a natural human emotion that everyone experiences. Additionally, teachers with high emotional levels added and highlighted the need of expressing and understanding sadness. "I think everyone has emotions ...when necessary, you need to talk to your close friends or family Seek comfort" ( T4 ) "We should not avoid the sadness, but accept our own emotions and figure out why such emotions occur." ( T3 )

\subsubsection{Views on young children's anger}

Three teachers assumed that everyone should be allowed to be angry but they have to adopt the appropriate way to express the anger. A teacher with a low emotional level did not share her perception of the emotion of anger but instead pointed out the hazardous side of responding aggressively which seems to be the instinctive, natural way to express anger. "I am very uncomfortable with children's way of expressing anger by using physical acts and when they hurt others, I will tell them sternly not to do that." ( T1 )

\subsection{The way teachers deal with children's grief and anger}

\subsubsection{Teachers' verbal responses to children's sadness and anger}

After combining and analyzing the collected data, teachers' verbal responses to children's negative emotions are shown in Table 2, including 1) ignoring: teachers' intentional or unintentional avoidance of children's emotional display; 2) emotion naming: teachers' use of emotional expressions such as sadness; 3) behavior focus: teachers' reminding children of the rules of the behavior; 4) problem focus: teachers' endeavor to solve children's emotional problems; 5) explaining: teachers' illustration of the reasons and the consequences of children's emotions; 6) comforting: teachers' expression of their concerning attitudes towards children's negative emotions; and 7) others. It is worth noting that teachers with high emotional levels did not ignore their pupils' unpleasant feelings; however, $23 \%$ of those emotions are largely ignored by teachers with low meta-emotional levels. In the classes with lower meta-emotional levels, more anger behaviors can be observed, which is approximately 7 times larger than the number of their high emotional counterparts. Additionally, teachers who are less conscious of their own emotions are obviously more concerned about children's behavior. And those who are highly sensitive to their own emotions encourage children to discuss the causes of negative emotions with their peer classmates. The problem focus method was frequently employed by teachers with higher meta-emotional level, which is 5 times more than that of teachers with low meta-emotional level.

Teachers from different groups demonstrated their different ways to deal with young children's sadness and anger. High meta-emotional teachers respect children's various emotions, allow them sufficient personal space, and provide them with problem-solving solutions. Furthermore, they also encourage youngsters to express their feelings. "When a child feels sad, I first accept his feelings and ask whether he is angry, disappointed, or sad. Then I will ask him the reason for his emotions, and work with him to dissolve his emotions. " ( T4 )

"Children who love to lose their temper may conduct a variety of annoying behaviors, such as being rude to their friends or themselves ...... but the teacher needs to observe more and communicate more with the children to understand what their real needs are." ( T4 )

Teachers with low meta-emotional levels said that they would provide physical comforting and actual explaining when the child was sad or angry. However, they did not emphasize the importance of emotional naming, nor did they encourage young children to solve their own emotional problems. Teacher 1 (T1) claimed that the youngsters become enraged when they do not fulfill all their desires. She also insisted that the children should not be forced to discuss their emotional problems as they need a space to calm down. As she commented: "Sometimes when children are emersed in the negative emotions and you stop them from releasing their feelings, they might be even angrier. "

Table 2: Teachers' verbal responses to children's sadness and anger

\begin{tabular}{|c|c|c|c|c|c|c|c|c|}
\hline Group & event & lgnoring & $\begin{array}{c}\text { Emotional } \\
\text { naming }\end{array}$ & $\begin{array}{c}\text { Behavior } \\
\text { focus }\end{array}$ & $\begin{array}{c}\text { Problem } \\
\text { focus }\end{array}$ & explaining & comforting & others \\
\hline $\begin{array}{c}\text { Low } \\
\text { meta-emot } \\
\text { ional level }\end{array}$ & $\begin{array}{c}64 \\
\text { (19 sadne } \\
\text { ss; } 45 \text { ang } \\
\text { er) }\end{array}$ & $\begin{array}{c}15 \\
(23 \%)\end{array}$ & $\begin{array}{c}2 \\
(3 \%)\end{array}$ & $23(36 \%)$ & $\begin{array}{c}6 \\
(9 \%)\end{array}$ & $\begin{array}{c}8 \\
(13 \%)\end{array}$ & $\begin{array}{c}3 \\
(5 \%)\end{array}$ & $\begin{array}{c}7 \\
(11 \%)\end{array}$ \\
\hline
\end{tabular}




\begin{tabular}{|c|c|c|c|c|c|c|c|c|}
\hline $\begin{array}{c}\text { High } \\
\text { meta-emot } \\
\text { ional level }\end{array}$ & $\begin{array}{c}29 \\
\left(\begin{array}{c}2 \text { sadne } \\
\text { ss; } 7 \\
\text { anger })\end{array}\right.\end{array}$ & 0 & $\begin{array}{c}3 \\
(10 \%)\end{array}$ & $\begin{array}{c}6 \\
(21 \%)\end{array}$ & $\begin{array}{c}9 \\
(31 \%)\end{array}$ & $\begin{array}{c}3 \\
(10 \%)\end{array}$ & $\begin{array}{c}4 \\
(14 \%)\end{array}$ & $\begin{array}{c}4 \\
(14 \%)\end{array}$ \\
\hline total & 93 & $\begin{array}{c}5 \\
(16 \%)\end{array}$ & $\begin{array}{c}5 \\
(5 \%)\end{array}$ & $\begin{array}{c}29 \\
(31 \%)\end{array}$ & $\begin{array}{c}15 \\
(16 \%)\end{array}$ & $11(12 \%)$ & 7 & $11(12 \%)$ \\
\hline
\end{tabular}

Note: The values in brackets reflect the percentage of events occurring within the group

\subsubsection{Teachers' nonverbal responses to young children's sadness and anger}

According to the observed events, teachers' nonverbal responses to children's negative emotions can be mainly divided into four categories: 1) comforting such as pats or hugs; 2) accompanying: the teacher keeping the same height with the child and keeping eye contact with the child; 3 ) controlling: the teacher trying to restrict children's behavior; 4) indifference: the teacher talking to the child from a distance without eye contacts.
As shown in Table 2, none of the teachers in the two groups used controlling behaviors to respond to children's negative emotions. Besides, teachers who are highly aware of their own emotions are 6 times more likely to comfort children by hugging, touching, or rubbing their backs when receiving signals that the children were angry. However, teachers with low meta-emotional awareness are prone to uphold indifferent attitudes towards children's depressed feelings.

Table 3: Teachers' nonverbal responses to young children's sadness and anger

\begin{tabular}{|c|c|c|c|c|c|c|}
\hline Group & event & Ignoring & comforting & accompanying & controlling & indifference \\
\hline $\begin{array}{c}\text { Low } \\
\text { meta-emotion } \\
\text { al level }\end{array}$ & $\begin{array}{c}64 \\
\text { (19 sadness; } \\
45 \text { anger) }\end{array}$ & $\begin{array}{c}15 \\
(23 \%)\end{array}$ & $\begin{array}{c}7 \\
(11 \%)\end{array}$ & $\begin{array}{c}13 \\
(20 \%)\end{array}$ & $\begin{array}{c}5 \\
(8 \%)\end{array}$ & $\begin{array}{c}23 \\
(36 \%)\end{array}$ \\
\hline $\begin{array}{c}\text { High } \\
\text { meta-emotion } \\
\text { al level }\end{array}$ & $\begin{array}{c}29 \\
\text { (22 sadness; } 7 \\
\text { anger) }\end{array}$ & 0 & $\begin{array}{c}12 \\
(41 \%)\end{array}$ & $\begin{array}{c}16 \\
(55 \%)\end{array}$ & 0 & $\begin{array}{c}1 \\
(4 \%)\end{array}$ \\
\hline total & 93 & $\begin{array}{c}15 \\
(16 \%)\end{array}$ & $\begin{array}{c}19 \\
(5 \%)\end{array}$ & $\begin{array}{c}29 \\
31 \%)\end{array}$ & $\begin{array}{c}5 \\
(5 \%)\end{array}$ & $\begin{array}{c}24 \\
(26 \%)\end{array}$ \\
\hline
\end{tabular}

Note: The values in brackets reflect the percentage of events occurring within the group

All teachers expressed their concerns about children with violent behaviors, assuming that when children became aggressive, they must be removed to another place to protect the other children. During the process, teachers with higher meta-emotional levels displayed more respect and employed supportive body language such as accompanying them by their side, as explained by Teacher 3 (T3).

\subsection{The teacher tries to teach about sadness and anger}

\subsubsection{What is the teacher trying to teach young children about sadness?}

High meta-emotion teachers tried to encourage children to accept, express, and digest the negative states of mind. "I think expressing feelings is the most important thing as every emotion should be valued and accepted. It is normal. " ( T4 )

Teachers in the low group were unsure what to teach about sadness, and they did not stress the significance of accepting or expressing grief. "I hope they can solve the problem in their own way, which is a good opportunity to learn to be independent." ( T2 )

\subsubsection{What is the teacher trying to teach young children about anger?}

As suggested by Teacher 3 (T3), higher meta-emotion teachers have certain objectives what to be imparted about anger. Although angry feelings are normal and acceptable, they should not be used as an excuse to harm themselves or others, which was not a suitable way of expressing feelings.

Teacher 4 (T4) also believed that teaching children about feelings would help them not only solve their problems in a more positive way when growing up but also understand themselves better. Teacher 1 (T1) did not mention the valuable significance of discussing the causes and the potential solutions of children's anger; however, she suggested that they should be accompanied and comforted. Teacher 2 (T2) intended to teach children how to control their behavior because this ability was rather necessary when she was young. 


\section{DISCUSSION}

\subsection{Both groups of teachers have correct perceptions of sadness and anger with high meta-emotional ones showing higher levels of awareness}

Through interviews and observations, findings can be revealed that both groups of teachers can recognize children's sadness and anger in a timely manner, accept the presence of these two kinds of emotions and respond to them in various ways. However, teachers with higher meta-emotional levels have gained a deeper insight into children's sadness and anger as they could provide more comprehensive descriptions when analyzing children's negative emotions. They can even define and classify those emotions based on whether the feelings were internal towards themselves or external towards others. Low meta-emotional teachers merely interpret their feelings of sadness and anger in a relatively thin and limited way.

\subsection{Both groups of teachers have an overall scientific conception of emotional education with high meta-emotional ones showing more purposeful behavior.}

The results of the interview show that two groups of teachers could uphold a scientific and rational attitude towards emotional education in general. Teachers with low meta-emotional levels presented a fragmented and random understanding of the goals and contents of emotion education while higher meta-emotional ones provided penetrating and revealing insights into the contents and methods of emotion education with a clearly stated and strong sense of purpose.

\subsection{A huge difference can be identified in the teaching activities of two groups of teachers with high meta-emotional ones showing more positive behaviors}

It can be concluded that teachers with different affective levels have many different perceptions and practices in emotional education. Teachers with higher meta-emotional levels often respond to, embrace, and appreciate children's emotions while also attempting to educate youngsters to manage their feelings appropriately. All these tendencies are all positive characteristics of teachers facing and dealing with children's emotions, which teacher education should emphasize and develop.

Although teachers with low meta-emotion levels highlighted the necessity of providing sufficient assistance, such as comforting and accompanying, when children experience sadness and anger, they overlooked the value of enabling children to voluntarily express them, which may be a hindrance to their healthy mental sanity.

\section{CONCLUSIONS}

This research was carried out in order to figure out teachers with different Meta-emotion level,their understanding and responses to children's negative emotions.The observation and interview results of this study revealed that kindergarten teacher's level of Meta-emotion related to their behaviors in responding to children's emotions.Furthermore,preschool teachers with high level of Meta-emotion frequently responed to their students' emotion and intended to position themselves at the children's level.They also accepted and valued children's emotions and they taught their students' emotions how to express emotions. On the contrary, although teachers with a low level of meta-emotions have a correct understanding of children's emotions, in teaching practice, they are more casual about how to educate children's emotions and show less support for the expression of children's emotions.

\section{LIMITATIONS AND PROSPECTS OF THE RESEARCH}

This research began with a focus on teachers' meta-emotions, investigating the differences in the views and practices adopted by teachers with varying meta-emotional levels to address children's negative emotions, which demonstrates valuable and innovative phenomena and viewpoints; however, there is still room for further improvement. First of all, the sample size of this study is relatively small and limited so special attention should be paid to generalize and transfer the findings identified in this study to all preschool teachers. Therefore, future research can expand the sample size and further discover the meta-emotional characteristics of preschool teachers and their influences on children's socializing practices. Secondly, three mechanisms for children's emotional socialization can be concluded from the previous studies: 1) the caregiver's response to children's emotions; 2) the caregiver's discussion on children's emotions; 3) the caregiver's way of expressing and digesting their own emotions. ${ }^{[13]}$ In this study, only the first two mechanisms were observed and explored. Accordingly, future investigation can be conducted to demonstrate the relationships between the strategic options that the teachers employed to handle their own feelings and their automatic responses to children's emotional expressions.

\section{REFERENCES}

[1] Gottman, J. Fainsilber-Katz, L. \& Hooven.Parental meta-emotion philosophy and the emotional life of 
families: Theoretical models and preliminary data [J]. Journal of Family Psychology, 1996, (10): 245-247.

[2] Ye Guanghui.Parents' Meta- emotional Concept Types and Measurements [C]. // Hu Taili, Xu Muzhu,Ye Guanghui.Emotions, Emotions and Culture: A Study of Cultural Psychology in Taiwanese Society [C]. Taipei: Central National Research Institute, 2002.

[3] $\mathrm{Xu}$ Yuan Li. Construction and role of dollar sentiment theory[J]. Xinyang Normal University, 2001, 21 (2): 67 - 71.

[4] Qi Yan, Lichuan Yun, Li Aijun. Yuan Mood Scale (TMMS) in the 1000 Revision and Application Recruits [J]. Journal of Health Psychology, 2003, 11 (3): 164 - 167.

[5] Eisenberg, N. (1996). Meta-emotion and socialization of emotion in the family - a topic whose time has come: Comment on Gottman et al. (1996). Journal of Family Psychology, 10, $269-276$.

[6] Lin Wenting. A study on the relationship between preschool teachers' emotional intelligence and children's emotional abilities [D]. National Taitung University, 2008.
[7] Sutton, RE \& Wheatley, KF (2003). Teachers' emotions and teaching: a review of the literature and directions for future research. Educational Psychology Review, 15 (4), 327-358.

[8] Zhang Hongyu. Research on teachers' coping styles of children's negative emotion expression events in middle class [D]. Baoding: Hebei University, 2016: 38-48.

[9] HEY J A. Child care teachers ' beliefs and practices regarding socialization of emotion in young children[J]. Journal of Early Childhood Teacher Education, 2005 (26): 283-295.

[10] Zhang Rui. Research on the Emotional Education View of Kindergarten Teachers [D]. Chongqing: Southwest University, 2007.

[11] Tao Yazhe. Research on Teachers' Strategies to Deal with Children's Negative Emotions [D]. Central China Normal University, 2018.

[12] Ying Yuhong. Strategies to relieve the negative emotions of children in small classes [J]. Journal of Ningbo Institute of Education, 2013, (4): 124-126.

[13] DeCourcey, WM (2004). Parents' meta-emotion attitudes and toddlers' emotion competencies. (Dissertation, Clark University, 2004). Dissertation Abstract International, 65 (09), 4 